\title{
Reclamation of old and partially oxidized tailings: performance of oxygen barrier covers
}

\author{
GABRIELLE DUBLET-ADLI ${ }^{1}$, THOMAS PABST ${ }^{2}$, GIJS \\ BREEDVELD $^{3}$, CHRISTIAN SÆTRE ${ }^{1}$, NARESH KUMAR ${ }^{4}$ \\ AND GUDNY OKKENHAUG ${ }^{5}$ \\ ${ }^{1}$ Norwegian Geotechnical Institute \\ ${ }^{2}$ Polytechnique Montreal \\ ${ }^{3}$ University of Oslo \\ ${ }^{4}$ University of Vienna \\ ${ }^{5}$ Norwegian University of Life Sciences \\ Presenting Author: gabrielle.dublet.adli@ngi.no
}

Sulfidic mine tailings can generate acid mine drainage (AMD) characterized by high concentrations of metals and sulfates and low pHs. Regulations and practice significantly improved in the last decades and several approaches were developed to better control the generation of acid mine drainage. Typically, in humid climate, mine tailings are covered to reduce infiltration of precipitation and limit oxygen diffusion.

The rehabilitation of older mine deposits is challenging and capping solutions with capillary barrier effect (CCBE) [1] have been suggested as a preferred closure solution. However, deposits that were abandoned for a long time are already weathered and the sulfidic minerals are oxidized, leading to highly acidic pore water and the precipitation of $\mathrm{Fe}$ (III)-rich secondary minerals. These minerals could easily be remobilized and $\mathrm{Fe}$ (III) could contribute to indirect sulfide oxidation under low $\mathrm{pH}$ conditions. To date, it is not clear if a CCBE solution would decrease the generation of acid mine drainage sufficiently.

Tailings from the abandoned mine of Folldal, Norway, are generating AMD with high concentrations of $\mathrm{Cu}$ which cause significant contamination in the Folldal river. These tailings were sampled and characterized in the laboratory. The objective of the presented study is to assess if an oxygen barrier is efficient to decrease significantly the acidity and the concentrations of toxic heavy metals in the leachates from the partially-oxydized sulfidic tailings. Long-term column experiments were conducted to determine the effect of a CCBE on sulfide oxidation and acid mine drainage generation.

Results of the nearly 2 year-long study showed that $\mathrm{pH}$ increased by nearly one unit compared to the control column without cover, and $\mathrm{Fe}, \mathrm{S}$ and $\mathrm{Cu}$ concentrations decreased after an initial lag-time of several months. $\mathrm{Cu}$ concentrations decreased below detection limit whereas $\mathrm{Fe}$ and $\mathrm{S}$ decreased by around $50 \%$ compared to concentrations in the control column without cover. The results suggest that $\mathrm{O}_{2}$ limitation can have significant beneficial effects and decrease $\mathrm{Cu}$ concentrations in the mine-tailing drainage composition. However, it is expected that it will take relatively long time before effects can be observed under field conditions.

[1] CRC Press, 2020 - Ed. B. Bussière \& M. Guittonny 